\title{
Efficacy of Povidone Iodine in Treatment of Active Chronic Suppurative Otitis Media
}

\author{
Ahmed M. Al-Abbasi, MBChB, FICMS (ORL) \\ Lecturer of Otorhinolaryngology \\ Basrah College of Medicine \\ Basrah, Iraq
}

\begin{abstract}
:
This is a double-blind prospective study done in Basra, Iraq, from February 1 to October 31, 2005.

Forty-eight patients with active chronic suppurative otitis media (CSOM) were included in this study. Full histories were obtained. Otological examinations and ear swabs for culture were done. Pure tone audiometry (PTA) was performed before and two weeks after treatment. All the patients studied were treated systemically by an appropriate dose of amoxicillin.

The most common isolated organism was staphylococcus aureus (25\%), followed by pseudomonas aeroginosa (18.8\%) and streptococcus pneumoniae (18.8\%).

Povidone iodine (betadine) 5\% solution, neomycin dexamethasone (neodexone) drops, and normal saline $0.9 \%$ were used as local therapy (ear drops) randomly for three equally divided groups of patients.

Complete improvement occurred in $81 \%$ of the patients using povidone iodine ear drops, compared with $69 \%$ using neomycin-dexamethasone drops and only $25 \%$ using normal saline drops. Further, improvement using povidone iodine occurred earlier than improvement using neomycin-dexamethasone and normal saline ear drops.

No complications were detected as a result of any of the above treatment modalities.
\end{abstract}

Key words: Povidone iodine, chronic suppurative otitis media

Introduction

Chr hronic suppurative otitis media (CSOM) is a chronic infection of the middle ear, defined as otorrhoea of at least two weeks duration in the presence of tympanic membrane perforation. ${ }^{1}$ Active CSOM contributes to a major proportion of the clini-

Requests for reprints should be directed to Ahmed M. Al-Abbasi, MBChB, FICMS (ORL)

Lecturer of Otorhinolaryngology

Basrah College of Medicine

Basrah, Iraq cal workload of an average otolaryngological practice. $^{2}$

Ototopical antibiotic treatment is more effective than systemic antibiotic therapy in eliminating otorrhoea in $\mathrm{CSOM}^{2-4}$, probably because irreversible tissue damage and fibrosis caused by infection renders systemic therapy less effective.

Neomycin is particularly valuable against Proteus and Staphylococcus aureus but is ineffective against gram-negative anaerobes and has limited action against Pseudomonas aeroginosa because of an increasing degree of resistance. The addition of a 
steroid to the antibiotic drop enhances it. ${ }^{5}$

Iodine has been used as an antiseptic for a long time. Its bactericidal effect was established at the end of $19^{\text {th }}$ century. ${ }^{6}$ It is effective against gram-negative, gram-positive, mycobacteria, treponema, fungi, viruses, and protozoa. ${ }^{6,7}$ Its unique biological effect is characterized by the lack of development of resistance. ${ }^{6}$ NASA developed Polyvinylpyrrolidone (povidone)-bound iodine for the Apollo program, and it was first used during the Apollo 11 space mission in 1969.6 Soon thereafter, it was adapted to medicine and has since dominated the arsenal of surgical disinfection. ${ }^{6}$ By in vivo testing the substance was found to be faster acting and more effective against a larger number of pathogens than locally administered combined antibiotics. ${ }^{8}$ The formation is suitable to exert its effect also in the presence of blood, serum, proteins, and necrotic tissue debris. ${ }^{9}$

\section{Aim of the study}

The aim of this study was to determine the efficacy of povidone iodine $5 \%$ solution in the treatment of chronic suppurative otitis media.

\section{Patients and methods}

This is a double-blind randomized prospective study done at the otolaryngology department in AlJumhori Hospital from February 1 to October 31, 2005.

Forty-eight patients exhibiting otorrhoea-associated recurrent suppurative otitis media with tympanic membrane perforation were included in this study. Their ages ranged from 11 to 67 with a mean of 26 years. Additional patients with CSOM were excluded because of cholesteatoma, marginal perforation, aural polyps, and associated otitis externa. Children younger than 10 years of age were also excluded. Swabs for culture were taken from all the studied patients. Pure tone audiometry (PTA) also was done before and two weeks after local treatment.

All the studied patients were treated systemically by the appropriate dose of amoxicillin, which is widely available locally.

Povidone iodine $(5 \%)$ solution (Betadine), neomycin-dexamethasone (Neodexon), and normal saline $(0.9 \%)$ in identical dark brown bottles, labeled only with a code number, were randomly given to the three studied groups of 16 patients each. The dose was three drops, three times daily for two weeks, before which time they were instructed to clean the ears with self-made cotton buds. The patients also were instructed to prevent water from gaining access into the ear. Assessment was based on symptomatology and examination, which were done after the first and second weeks of treatment.

I used a simple scoring system for assessment of improvement (Table 1). It included the presence or absence of tinnitus, ear discharge and its amount and type, middle ear mucosal congestion and edema, and the hearing threshold represented by air-bone gap (ABG). Patients then were classified based on their assessment scores: complete improvement (810), partial improvement (4-7), no improvement (0$3)$, and deterioration $(<0)$.

\section{Results}

Table 2 shows the results of ear swab cultures of the studied patients.

Staphylococcus aureus was the most common organism, observed in 12 (25\%) patients, followed by pseudomonas and streptococcus pneumonia in 9 (18.7\%) patients each. In nine patients no growth was detected.

Table 3 shows the improvement of CSOM according to the different local therapies. Eighty-one percent of those treated by Betadine were completely improved, $12 \%$ partially improved, $6 \%$ not improved, and none deteriorated. Eleven patients (69\%) of those who used Neodexone drops were completely improved, three patients (19\%) were partially improved and $12 \%$ had no improvement. Normal saline drops showed discouraging results. Only 4 patients (25\%) showed complete improvement, 2 (12\%) had partial improvement, and 10 patients had no improvement (62\%).

There were no morbidities of the therapies including burning, stinging or local inflammation of the ear canal that would limit the drop use.

\section{Discussion}

Figure 1 shows organisms cultured in different studies ${ }^{10}$ compared to our study. The difference may be attributed to the widespread self-use of antibiotics in our patients, which changes the environment of organisms. The causes of the negative culture results in nine patients are probably anaerobic infection, laboratory error or antibiotics taken before culture.

Improvement is usually expressed as cure of 
Table 1. Proposed scoring system.

\section{Parameter}

\begin{tabular}{|c|c|c|c|c|c|c|c|c|}
\hline Tinnitus & No & 2 & Decreased & 1 & Same & 0 & Increased & -1 \\
\hline Amount of Discharge & No & 2 & Decreased & 1 & Same & 0 & $\begin{array}{l}\text { Increased } \\
\text { or pulsatile }\end{array}$ & -1 \\
\hline Type of Discharge & No & 2 & Mucoid & 1 & $\begin{array}{l}\text { Muco- } \\
\text { purulent }\end{array}$ & 0 & Purulent & -1 \\
\hline $\begin{array}{l}\text { Mucosal Congestion/ } \\
\text { Edema }\end{array}$ & No & 2 & Mild & 1 & Same & 0 & Increased & -1 \\
\hline Air-bone gap by PTA & $\begin{array}{l}\text { Significant } \\
\text { decrease }\end{array}$ & 2 & $\begin{array}{l}\text { Insignificant } \\
\text { decrease }\end{array}$ & 1 & Same & 0 & Increase & -1 \\
\hline
\end{tabular}

otorrhoea and middle ear mucosal inflammation. ${ }^{11,12}$ The proposed scoring system is probably a better method of assessing improvement as it includes other criteria (Table I) and is easy to use. The use of povidone iodine (5\%) was associated with $81 \%$ complete improvement (13 patients) after the treatment course, and the interesting fact is that the improvement occurred earlier than the improvement associated with the use of Neodexon drops and normal saline.

It is known that amoxicillin has little activity against the most common pathogens in the present study (Staph. aureus and Pseudomonas aeroginosa) but the noted improvement may be attributed to the effect of local therapy.

In the present study there were no signs, symptoms or pure audiometric data, suggesting ototoxicity. Porez et $\mathrm{al}^{13}$ and Aursenea ${ }^{14}$ reported no ototoxic effect using povidone iodine (Betadine) solution.

Oberg and Lindsey ${ }^{15}$ recommended not to use povidone iodine in a wound because of its cytotoxicity. However, the cytotoxic effect was shown only in vitro. ${ }^{16}$ No allergic reaction was reported during the use of povidone iodine solution in this study, which is consistent with others' findings. ${ }^{17-19}$

The use of povidone iodine appears to be an effective treatment of CSOM. It is widely available and exceptionally affordable. It is probably the ideal form of local treatment, especially in developing countries.

\section{References}

1. WHO/CIBA Foundation Workshop. Prevention of hearing impairment from chronic otitis media (WHO/PHD/98.4). Held in London, UK, 19-21
Table 2. Types of organisms in patients with CSOM.

\begin{tabular}{lrc}
\hline Type of Organism & Number & Percent \\
\hline Staphylococcus aureus & 12 & 25.0 \\
Pseudomonas aeroginosa & 9 & 18.8 \\
Streptococcus pneumonia & 9 & 18.8 \\
Proteus sp & 4 & 8.3 \\
Klebsiella sp & 3 & 6.3 \\
E. coli & 2 & 4.2 \\
No growth & 9 & 18.8 \\
& & \\
Total & 48 & 100 \\
\hline
\end{tabular}

November 1996. Geneva: World Health Organization, 1998. Also available from http://bit.ly/10LXkKh. [Updated 2000 Apr 14; Accessed 2006 Aug 18]

2. Abbasi AM. Comparative study of different modalities of medical treatment of CSOM. Basrah Journal of Surgery. 2004;10:42-50.

3. Acuin J, Smith A, Mackenzie I. Intervention for CSOM (Cochrane review). In: The Cochrane Library, Issue 1, 2003. Oxford: update software.

4. Youngs R. Chronic suppurative otitis mediamucosal disease. In: Lunman $\mathrm{H}$, Wright $\mathrm{T}$, eds. Disease of the Ear. $6^{\text {th }}$ ed. London, England: Edward Arnold Publishers Ltd; 1998: 374-85.

5. Alper CM, Dohar JE, Gulhan M, et al. Treatment of chronic suppurative otitis media with topical tobramycin and dexamethasone. Arch Otolaryngol Head Neck Surg. 2000 Feb;126:165-73. PMID:10680867 6. Juhasz I. Experiences with the use of povidoneiodine-containing local therapeutics in dermatological surgery and in the treatment of burns: testing for allergic sensitization in postsurgery patients. 
Table 3: Improvement according to different type of local therapy.

\begin{tabular}{lllllll}
\hline Improvement & \multicolumn{2}{c}{ Betadine 5\% } & \multicolumn{2}{c}{ Neodexone } & \multicolumn{2}{c}{ Normal saline } \\
& No. & \% & No. & $\%$ & No. & \% \\
\hline Complete improvement & 13 & 81 & 11 & 69 & 4 & 25 \\
Partial improvement & 2 & 12 & 3 & 19 & 2 & 12 \\
No improvement & 1 & 6 & 2 & 12 & 10 & 62 \\
Deterioration & 0 & 0 & 0 & 0 & 0 & 0 \\
Total & 16 & & 16 & & 16 \\
\hline
\end{tabular}

Dermatology. 2002;204 Suppl 1:52-8. http://doi.org/bhfxbh

7. Fleischer $\mathrm{W}$, Reimer $\mathrm{K}$. Povidone-iodine in antisepsisstate of the art. Dermatology. 1997;195 Suppl 2:3-9. http://doi.org/bwn68r

8. Stahl-Bayliss CM, Grandy RP, Fitzmartin RD, et al. The comparative efficacy and safety of $5 \%$ povidone-iodine cream for topical antisepsis. Ostomy Wound Manage. 1990 Nov-Dec;31:40-9.

9. Hieholzer $G$, Reimer $K$, Weissenbacher ER. Topische Infektionstherapie und Prophylaxe. S. 18. G. Thieme: Verlag, Stuttgart, 1996.

10. Shenoi PM. Management of

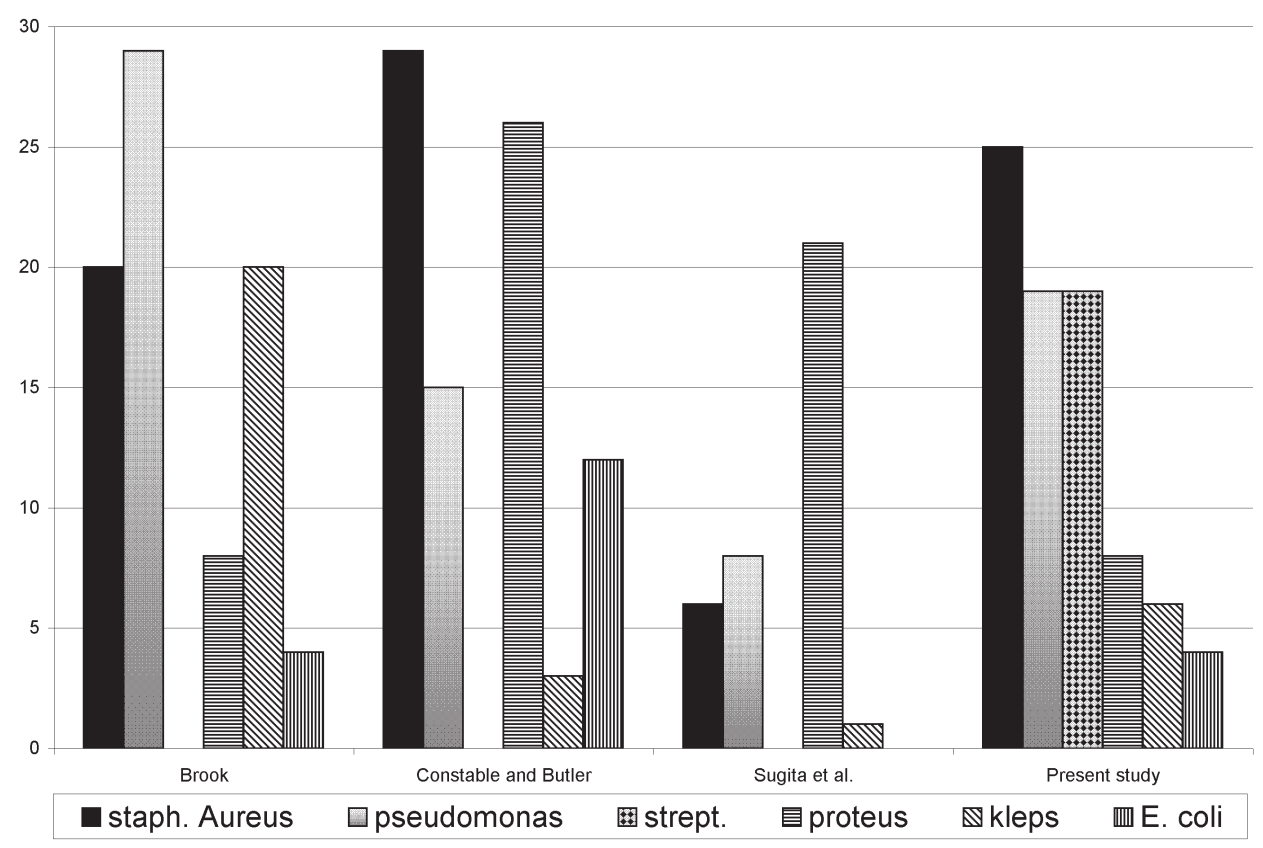

Figure 1. Comparison of bacteriology of CSOM in different studies.

CSOM. In: Booth JB Scott-Brown's otolaryngology. $5^{\text {th }}$ ed. Butterworth, 1987; 215-37.

11. Couzos S, Lea T, Mueller R, et al. Effectiveness of ototopical antibiotics for chronic suppurative otitis media in Aboriginal children: a community-based, multicentre, double-blind randomised controlled trial. Med J Aust. 2003;179:185-90. PMID: 12914507

12. Supiyaphun P, Kerekhanjanarong V, Koranasophonepun J, et al. Comparison of ofloxacin otic solution with oral amoxycillin plus chloramphenicol ear drop in treatment of chronic suppurative otitis media with acute exacerbation. J Med Assoc Thai. 2000 Jan;83:61-8. PMID: 10710871

13. Perez R, Freeman S, Sohmer H, et al. Vestibular and cochlear ototoxicity of topical antiseptics assessed by evoked potentials. Laryngoscope. 2000;110:1522-7. http://doi.org/bc56bn

14. Aursnes J. Ototoxic effect of iodine disinfectants.

Acta Otolaryngol. 1982 Mar-Apr;93:219-26. PMID: 6977984

15. Oberg MS, Lindsey D. Do not put hydrogen peroxide or povidone iodine into wounds! Am J Dis Child. 1987 Jan;141:27-8. PMID: 3788878

16. Damour O, Hua SZ, Lasne F, et al. Cytotoxicity evaluation of antiseptics and antibiotics on cultured human fibroblasts and keratinocytes. Burns. 1992 Dec;18:479-85. http://doi.org/bsjk3k

17. Ancona A, Suárez de la Torre R, Macotela E. Allergic contact dermatitis from povidone-iodine. Contact Dermatitis. 1985;13:66-8. http://doi.org/d88stn

18. Tosti A, Vincenzi C, Bardazzi F, et al. Allergic contact dermatitis due to povidone-iodine. Contact dermatitis. 1990 Sep;23:197-8. http://doi.org/cq7g6t 19. Okano M. Irritant contact dermatitis caused by povidone-iodine. J Am Acad Dermatol. 1989 May;20(5 Pt 1):860. http://doi.org/cqhnvs 